\title{
A longitudinal study on the predictive validity of the fear-avoidance model in low back pain
}

Citation for published version (APA):

Sieben, J. M., Vlaeyen, J. W. S., Portegijs, P. J. M., Verbunt, J. A. M. C. F., van Riet-Rutgers, S., Kester, A. D. M., von Korff, M., Arntz, A. R., \& Knottnerus, J. A. (2005). A longitudinal study on the predictive validity of the fear-avoidance model in low back pain. Pain, 117, 162-170.

https://doi.org/10.1016/j.pain.2005.06.002

Document status and date:

Published: 01/01/2005

DOI:

10.1016/j.pain.2005.06.002

Document Version:

Publisher's PDF, also known as Version of record

Document license:

Taverne

Please check the document version of this publication:

- A submitted manuscript is the version of the article upon submission and before peer-review. There can be important differences between the submitted version and the official published version of record.

People interested in the research are advised to contact the author for the final version of the publication, or visit the DOI to the publisher's website.

- The final author version and the galley proof are versions of the publication after peer review.

- The final published version features the final layout of the paper including the volume, issue and page numbers.

Link to publication

\footnotetext{
General rights rights.

- You may freely distribute the URL identifying the publication in the public portal. please follow below link for the End User Agreement:

www.umlib.nl/taverne-license

Take down policy

If you believe that this document breaches copyright please contact us at:

repository@maastrichtuniversity.nl

providing details and we will investigate your claim.
}

Copyright and moral rights for the publications made accessible in the public portal are retained by the authors and/or other copyright owners and it is a condition of accessing publications that users recognise and abide by the legal requirements associated with these

- Users may download and print one copy of any publication from the public portal for the purpose of private study or research.

- You may not further distribute the material or use it for any profit-making activity or commercial gain

If the publication is distributed under the terms of Article $25 \mathrm{fa}$ of the Dutch Copyright Act, indicated by the "Taverne" license above, 


\title{
A longitudinal study on the predictive validity of the fear-avoidance model in low back pain
}

\author{
Judith M. Sieben $^{\mathrm{a}, \mathrm{d}, *}$, Johan W.S. Vlaeyen ${ }^{\mathrm{b}, \mathrm{d}, \mathrm{f}}$, Piet J.M. Portegijs ${ }^{\mathrm{a}, \mathrm{e}}$, Jeanine A. Verbunt ${ }^{\mathrm{g}}$, \\ Sita van Riet-Rutgers ${ }^{\mathrm{a}, \mathrm{b}, \mathrm{d}}$, Arnold D.M. Kester ${ }^{\mathrm{c}, \mathrm{e}}$, Michael Von Korff ${ }^{\mathrm{h}}$, \\ Arnoud Arntz ${ }^{\mathrm{b}, \mathrm{d}}$, J. André Knottnerus ${ }^{\mathrm{a}, \mathrm{e}}$ \\ ${ }^{a}$ Department of General Practice, Maastricht University, P.O. Box 616, 6200 MD Maastricht, The Netherlands \\ ${ }^{\mathrm{b}}$ Department of Medical, Clinical, and Experimental Psychology, Maastricht University, Maastricht, The Netherlands \\ ${ }^{\mathrm{c}}$ Department of Methodology and Statistics, Maastricht University, Maastricht, The Netherlands \\ ${ }^{\mathrm{d}}$ Experimental Psychopathology Research Institute (EPP), Maastricht University, Maastricht, The Netherlands \\ ${ }^{\mathrm{e}}$ Care and Public Health Research Institute (CAPHRI), Maastricht University, Maastricht, The Netherlands \\ ${ }_{\mathrm{f}}^{\mathrm{f}}$ ain Management and Research Center, University Hospital Maastricht, Maastricht, The Netherlands \\ ${ }^{\mathrm{g}}$ Rehabilitation Foundation Limburg, Hoensbroek, The Netherlands \\ ${ }^{\mathrm{h}}$ Center for Health Studies, Group Health Cooperative, Seattle, USA
}

Received 9 December 2004; received in revised form 26 May 2005; accepted 6 June 2005

\begin{abstract}
Recently, fear-avoidance models have been quite influential in understanding the transition from acute to chronic low back pain (LBP). Not only has pain-related fear been found to be associated with disability and increased pain severity, but also treatment focused at reducing pain-related fear has shown to successfully reduce disability levels. In spite of these developments, there is still a lack in well-designed prospective studies examining the role of pain-related fear in acute back pain. The aim of the current study was to prospectively test the assumption that pain-related fear in acute stages successfully predicts future disability. Subjects were primary care acute LBP patients consulting because of a new episode of LBP ( $\leq 3$ weeks). They completed questionnaires on background variables, fear-avoidance model variables and LBP outcome (Graded Chronic Pain Scale, GCPS) at baseline, 3, 6, and 12 months follow-up and at the end of the study. Twohundred and twenty-two acute LBP patients were included, of whom 174 provided full follow-up information (78.4\%). A backward ordinal regression analysis showed previous LBP history and pain intensity to be the most important predictors of end of study GCPS. Of the fearavoidance model variables, only negative affect added to this model. Our results do not really support the longitudinal validity of the fearavoidance model, but they do feed the discussion on the role of pain-related fear in early stages of LBP.
\end{abstract}

(C) 2005 Published by Elsevier B.V. on behalf of International Association for the Study of Pain.

Keywords: Low back pain; Fear-avoidance model; Ordinal regression analysis; General practice

\section{Introduction}

Back in 1996, Gordon Waddell (1996) called nonspecific low back pain (LBP) "a twentieth century health care enigma". Now, we have come to the twenty-first

\footnotetext{
* Corresponding author. Address: Department of General Practice, Maastricht University, P.O. Box 616, 6200 MD Maastricht, The Netherlands. Tel.: + 31 433882187; fax: + 31433619344 .

E-mail address: judith.sieben@hag.unimaas.nl (J.M. Sieben).
}

century, and still the puzzle has not been solved. With lifetime incidence rates as high as $70-85 \%$ (Andersson, 1999), LBP is one of the most important medical problems in western societies. Although self-limiting in most cases, many face recurrences and some even develop a chronic condition, with severe consequences for both patients and society.

As Pincus et al. (2002) pointed out in their review, the importance of psychosocial factors in LBP is well accepted, and evidence-based clinical guidelines on LBP are 
consistent in adopting a biopsychosocial perspective (Bekkering et al., 2001; Faas et al., 1996; Kendall et al., 1997). A specific theoretical concept developed over the last decade in chronic LBP patients is the fear-avoidance model (Vlaeyen and Linton, 2000). The basic tenet of the fearavoidance model is that when LBP is being misinterpreted as a sign of serious injury, patients (especially those in negative mood who tend to catastrophize about their pain) might develop pain-related fear and subsequent avoidance of movements that are believed to be harmful. Persisting avoidance behaviour will cause increasing disability and physical deconditioning as a result of inactivity. Fearful patients are at risk of becoming trapped in a cycle of pain, fear, disability, and depressive symptoms.

Several studies addressed the predictive value of acute stage fear-avoidance variables in explaining LBP prognosis. Research done by Fritz et al. (2001) showed fearavoidance beliefs to predict disability and work status 4 weeks later, even after controlling for initial levels of pain and impairment. Klenerman et al. (1995) reported fearavoidance variables to be the strongest predictors for 12 month course of LBP. In the general population, painrelated fear and pain catastrophizing predicted LBP and disability 6 months later (Picavet et al., 2002). Similar results were found by Buer and Linton (2002), showing a relationship between fear-avoidance and activities of daily living in a sample of pain-free individuals and patients with non-chronic spinal pain. Linton et al. (2000) suggested that fear-avoidance beliefs are related to the inception of LBP. Finally, previous research by our group (Sieben et al., 2002) showed that rising fear during the first 2 weeks of a new LBP episode was associated with higher disability at 1-year follow-up. In contrast, only one study was traced in which fear-avoidance beliefs were not retained in a multivariate model including several psychological predictors in a mixed sample of acute and subacute LBP patients (Burton et al., 1995).

The methods used in these previous studies are very diverse with respect to sample selection, follow-up time, outcome measures, predictor variables, and analyses. Although the results are important, generalisation is difficult and more rigorous prospective studies are needed. Aim of the present study is to test the longitudinal validity of the fear-avoidance model; the research question to be answered is whether acute stage pain-related fear predicts long-term LBP outcome after adjustment for known risk factors.

\section{Methods}

\subsection{Subjects}

Patient recruitment was carried out from January 2001 to April 2003 by 35 Dutch general practices joined in the Coordination Centre Primary Care (CEL) and/or the Registration Network of Family Practices (RNH) (Metsemakers et al., 1992). Both CEL and
RNH are primary care research networks affiliated to the Department of General Practice of Maastricht University.

The general practitioners (GPs) invited primary care patients who consulted because of a new episode of non-specific LBP to participate in this study. A new episode of LBP was defined as: (1) pain localised below the scapulae and above the gluteal folds (following IASP taxonomy; Merskey and Bogduk, 1994); (2) time since pain onset no longer than 3 weeks; (3) after at least 3 months without relevant activity limitations due to LBP.

Exclusion criteria were (1) age younger than 18 or older than 60 years, (2) (suspected) specific cause of LBP (such as lumbar disc herniation with neurological complaints, tumour or vertebral fracture), (3) other major disease or psychiatric disorder (as far as known to the GP), (4) pregnancy, and (5) insufficient knowledge of Dutch language to complete a questionnaire. Selection criteria were initially checked by the GPs and later rechecked by the researchers.

After the GP-consultation, eligible patients received full written information about the study to read at home. Within the next days, potential participants were contacted by phone. Any questions about the study were answered, and when agreeing on participation the patient was asked to return the baseline questionnaire together with the signed informed consent form.

\subsection{Ethics}

The study protocol was approved by the medical ethics review committees of Maastricht University Hospital and Maastricht University (Maastricht, The Netherlands) and the Institute for Rehabilitation Research (Hoensbroek, The Netherlands).

\subsection{Baseline questionnaire}

Within a few days after the GP visit participants completed the baseline questionnaire. This questionnaire consisted of (a) a set of descriptives such as work status, back pain history, and characteristics of the current episode and (b) measures concerning the fear-avoidance model.

\subsubsection{Work status}

To explore the occupational context, items covering employment status, occupation, sick leave, and job satisfaction were included in the questionnaire.

\subsubsection{Back pain history}

The patient's back pain history was characterised by the number of episodes in the past, age at which the first episode occurred and history of back pain treatment. Both work status and back pain history items were designed for this study (but based on previous questionnaires).

\subsubsection{Current LBP episode}

The current LBP episode was described by (a) type of pain onset (sudden/gradual) and (b) presence of radiating symptoms (yes/no). Both these items are derived from the McGill Pain Questionnaire, Dutch Version (Verkes et al., 1989). An additional item covered acute pain duration (number of days since LBP onset). 


\subsubsection{Pain intensity}

Pain intensity was measured by a $10 \mathrm{~cm}$ Visual Analogue Scale (VAS) with extremes of 0 ('no pain') and 100 ('unbearable pain') (Jensen and Karoly, 1992).

\subsubsection{Negative affect}

Negative affect was assessed by the Dutch Version of the Negative Emotionality Scale (NEM), which contains 14 dichotomous items derived from the Multidimensional Personality Questionnaire (Stegen et al., 1998). The NEM does not contain any items concerning somatic complaints. The Dutch version NEM scale is known for good reliability and validity (Crombez et al., 1999; Stegen et al., 1998).

\subsubsection{Pain catastrophizing}

A Dutch version of the Pain Catastrophizing Scale (PCS) (Sullivan et al., 1995) was used in this study to determine patients' thoughts and feelings about pain. This scale consists of 13 items. Patients indicate on a 5-point scale the extent to which they have an exaggerated negative view of their pain. The PCS has been shown to have good reliability and validity (Osman et al., 1997; Van Damme et al., 2002).

\subsubsection{Pain-related fear}

The level of pain-related fear was measured by the Tampa Scale for Kinesiophobia (Dutch Version) (Miller et al., 1991; Vlaeyen et al., 1995). This 17-item 4-point scale questionnaire was designed for use in back pain populations. Two subscales represent constructs of somatic focus (five items) and activity avoidance (eight items). Reliability and validity of the TSK Dutch version and its subscales are good (Roelofs et al., 2004; Vlaeyen et al., 1995).

\subsubsection{Physical disability}

To assess LBP related physical disability, the Quebec Back Pain Disability Scale (QBPDS) (Kopec et al., 1996) was used, which was developed specifically for LBP populations. To express the level of difficulty experienced in performing activities in daily life, patients rate a 6 -point Likert scale $(0=$ 'no difficulty' to $5=$ 'not able to do') for 20 selected activities such as getting dressed, climbing the stairs, and making the bed. The Dutch version is both reliable and valid (Schoppink et al., 1996).

\subsubsection{Social interference}

As recommended by Deyo et al. (1998), interference of LBP with social functioning is measured by a set of items covering absence from work and/or other normal daily activities, sports, leisure time activities, and time spent in bed because of LBP. These items are derived from the National Health Interview Survey, have been validated for use in LBP patients by Patrick et al. (1995), and were successfully applied before in the Maine Lumbar Spine Study (Atlas et al., 1996; Patrick et al., 1995). For use in the present study the questions have been translated into Dutch.

\subsubsection{0. (Avoidance of) physical activity}

The Physical Activity Rating Scale (PARS) (Vercoulen et al., 1997) was used to determine to what extent subjects engage in daily life activities (e.g. shopping, $1 \mathrm{~h}$ walking). Patients were asked to indicate on a 5-point scale ('never' to 'very often') whether they had performed each of 20 activities over the previous 2 weeks. The PARS was initially developed for application in chronic fatigue syndrome and was previously used in low back pain research by Verbunt et al. (in press). For this study, a newly designed question was added to the PARS scale to measure physical avoidance behaviour. After having rated activity frequencies, patients were asked for each item whether they would have performed the activity more often if they would not have taken their back pain into account. The sum of all 20 dichotomous answers (yes $=1$, no $=0$ ), with higher scores indicating more avoidance behaviour, was used as a measure of avoidance in our analysis.

\subsubsection{Depression}

The level of depression was assessed using the Beck Depression Inventory (BDI) (Beck et al., 1961). The BDI consists of 21 items and is a widely used self-report measure of depressive symptoms in clinical and non-clinical populations. Answers are on a 4-point scale, and two subscales reflect a negative view of self (six items) and a somatic factor (seven items) (Morley et al., 2002). The somatic factor was not evaluated in this study because of its conceptual overlay with other measures (TSK, PCS); only the 'negative view of self' subscale was used in analysis. Validity and reliability of the Dutch version of the BDI are well established (Bosscher et al., 1986).

\subsection{Follow-up}

Follow-up questionnaires containing all measures related to the fear-avoidance model (pain intensity, negative affect, pain catastrophizing, pain-related fear, physical disability, social interference, avoidance of activities, depression) were sent by mail to the participants at 3,6, and 12 months after the index GP visit. Non-responders were first reminded by telephone, and if necessary, received a written reminder together with another copy of the questionnaire.

At the end of the project (April 2004), when 12-months' followup for all participants were complete, a brief questionnaire assessing LBP outcome was sent to all participants at the same time (thus achieving a maximum follow-up of 40 months for those patients first enrolled in January 2001). A maximum of one reminder was sent to enhance response to this final cross-sectional measurement.

\subsection{Outcome}

As a primary outcome the Graded Chronic Pain Scale (GCPS) (Von Korff et al., 1992) was used. This instrument was developed from the point of view that primary care LBP should not be regarded as either acute or chronic depending on the duration of the complaints, but rather as recurrent episodes characterised by variable severity. The GCPS consists of seven items measuring aspects of pain, physical disability, and social interference resulting in a 5-class hierarchical scale: $0=$ no pain problem, $\mathrm{I}=$ low disability/low pain intensity, II=low disability/high pain intensity, III = high disability/moderately limiting, IV=high disability/severely limiting. The low range of this pain grading is typically characterised by pain intensity levels, while the high range of the scale is described by differences in disability levels. Differences between grades were shown to be clinically relevant (Von Korff et al., 1992). Higher GCPS grades were found to be associated with higher levels of pain, disability and depression, 
poor self-reported quality of health, more doctor visits and higher health care costs (Engel et al., 1996; Penny et al., 1999; Smith et al., 1997; Von Korff et al., 1992). Its responsiveness to changes over time was shown to be good (Elliott et al., 2000).

In the present study, the Graded Chronic Pain Scale was applied at the cross-sectional end of study measurement. For all other measurements, an adaptation of the GCPS classification was derived from scores on pain, physical disability and social interference measures (details available from corresponding author). Calculation methods were refined by expert opinion and validated by comparison with data from similar samples (Von Korff, 2001; Von Korff et al., 1993).

\subsection{Analysis}

SPSS 11.5 (SPSS, Chicago, USA) was used for all statistical analyses. Because most variables showed non-normal distributions, non-parametric statistics were applied. Unless reported otherwise, statistical tests are two-sided and $P$-values $\leq 0.05$ are judged significant.

Bivariate associations between fear-avoidance model variables as assessed at baseline and LBP outcome (GCPS) at each of the follow-up moments were examined by Spearman rank correlation coefficients.

\subsubsection{Primary analysis}

Eight known or presumed 'standard' risk factors (age, gender, number of days since pain onset, number of previous episodes, radiating symptoms (yes/no), type of onset (sudden/gradual), level of education, pain intensity) were evaluated for their contribution in explaining outcome (GCPS at end of study). Because of distinct non-normality of the outcome scores, an ordinal regression model (available through SPSS procedure PLUM (polytomous logit universal models)) was used. First, a backward regression analysis was applied to determine a restricted subset of these variables for use in subsequent analyses. Next, the additional predictive value of baseline pain-related fear variables was tested. The standard risk factors resulting from the previous analysis were forced into the model and were kept. Then baseline TSK-somatic focus, TSKactivity avoidance, disability (QBPDS), follow-up time and interaction effects (fear-avoidance variables by follow-up time) were added and possibly deleted as part of the backward strategy. For each removal step likelihood-ratio tests were used to test the significance of the change in -2 loglikelihood. Steps were repeated until all remaining variables were significant contributors to the model or until no variables were left to delete. For each variable in the final model parameter estimates, odds ratios and 95\% confidence intervals were calculated.

\subsubsection{Secondary analysis}

Similar analyses were performed using 3, 6, and 12 months' chronic pain grades (GCPS) scores as a dependent variable successively (without testing for interaction effects as follow-up intervals were constant). Furthermore, the value of 3 and 6 months' fear-avoidance variables in predicting end of study GCPS was tested using the same strategy as in primary analysis. Finally, analyses were repeated once more entering all baseline fearavoidance variables together as independent variables to determine the predictive value of the entire fear-avoidance model.

\section{Results}

\subsection{Subject characteristics}

The GPs invited 464 of their patients to participate. Of them, 81 refused to participate, $136 \mathrm{did}$ not meet the selection criteria (mostly because of pain duration $>3$ weeks) and 25 with TSK scores $\geq 42$ were excluded because they participated in the intervention group of a trial study (RCT) that was conducted within the cohort. Selection criteria were met and informed consent was given by 222 general practice acute LBP patients. General characteristics of this sample are presented in Table 1 . The majority of patients consulted their GP within 1 week from LBP onset (median $=5$ days; interquartile range 2-10).

Table 1

Subject characteristics at baseline $(N=222)$

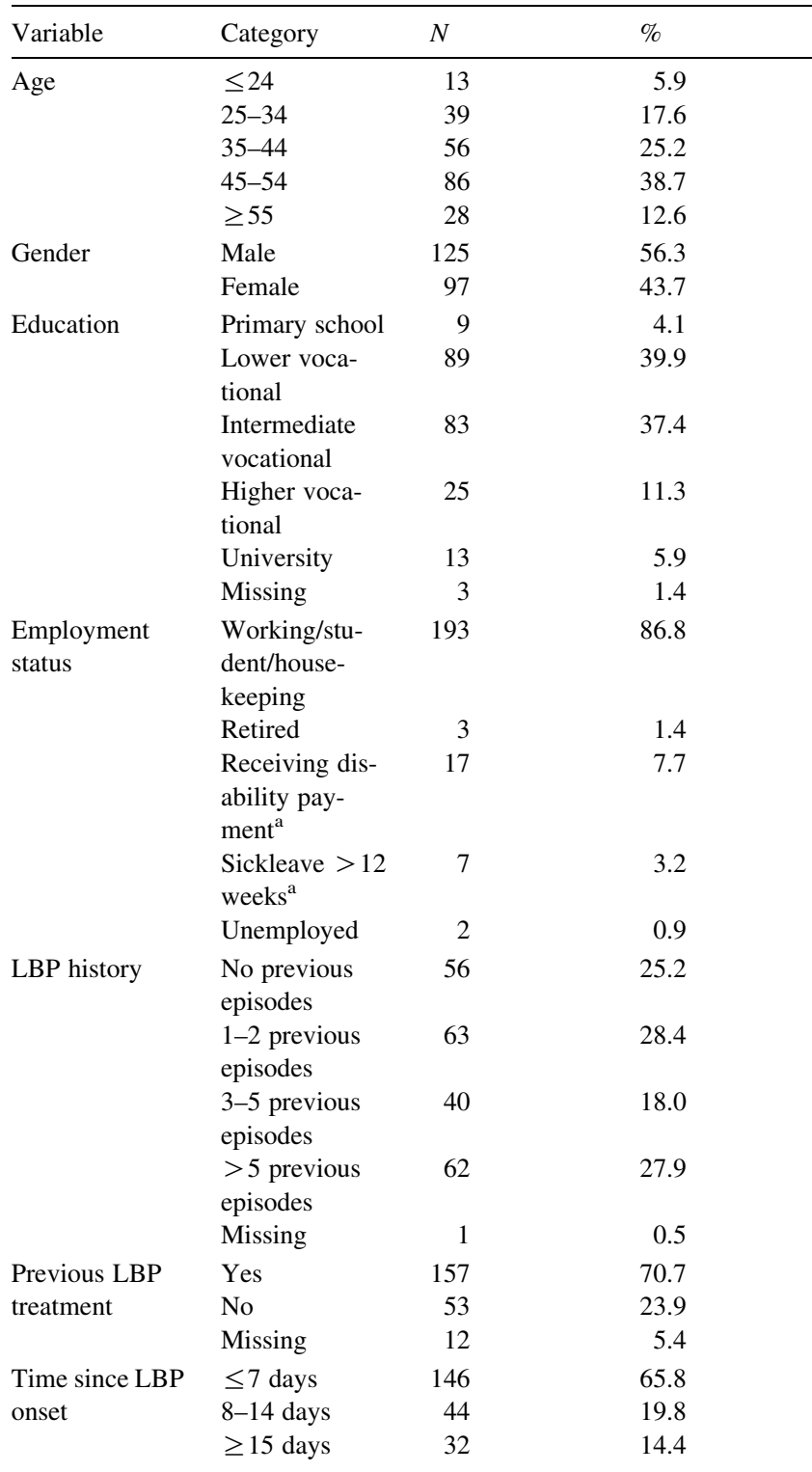

${ }^{\text {a }}$ Disability retirement/sickleave not necessarily due to LBP. 
Table 2

Response rates

\begin{tabular}{lll}
\hline & $N$ & $\%$ \\
\hline Selection criteria and informed consent $^{\mathrm{a}}$ & 222 & 100.0 \\
Baseline $^{\mathrm{b}}$ & 220 & 99.1 \\
3 months $^{\mathrm{b}}$ & 180 & 81.1 \\
6 months $^{\mathrm{b}}$ & 168 & 75.7 \\
12 months $^{\mathrm{b}}$ & 171 & 77.0 \\
End of study $^{\mathrm{b}}$ & 174 & 78.4
\end{tabular}

a Number of participants included.

${ }^{\mathrm{b}}$ Number of questionnaires returned.

About three-quarters of the participants reported a history of back pain. There were no significant differences (age, gender) between participants and non-participants (data were available from 89 non-participants).

\subsection{Follow-up}

Response rates during follow-up are shown in Table 2. No differences were found between responders and nonresponders, except for age; non-responders tended to be younger (significant at 12 months and end of study). The end of study cross-sectional data collection resulted in a median follow-up time of 1.9 years $($ minimum $=1.1$; maximum $=3.1$ years). Follow-up data covered a total amount of 327.7 patient years.

\subsection{Outcome}

Frequencies of Graded Chronic Pain Scale scores are reported in Fig. 1. Although many participants reported to be free of pain during follow-up, the largest group was categorized at grade I (low disability-low pain). About 15\% of all patients showed poor outcome (grades III and IV). Spearman's correlation between GCPS-scores as measured with the original instrument (end of study) and the adapted GCPS-scores at 12 months was 0.701 for those who completed both questionnaires within a 3 months' time span. This sufficient consistency suggests that the adaptation of the GCPS instrument was performed successfully.

\subsection{Associations between fear-avoidance variables and LBP outcome}

Table 3 shows descriptives of fear-avoidance model variables at baseline and correlations with follow-up chronic pain grades (GCPS). Significant but weak associations were found between end of study GCPS and all fearavoidance variables except TSK-somatic focus. For shorter follow-up intervals only pain catastrophizing and avoidance of activity appeared to be associated with chronic pain grade. The BDI subscale 'negative view of self' was only significantly related to outcome at 6 and 12 months. Both TSK subscales were associated to baseline GCPS scores but not to follow-up. Note that the correlations found for pain

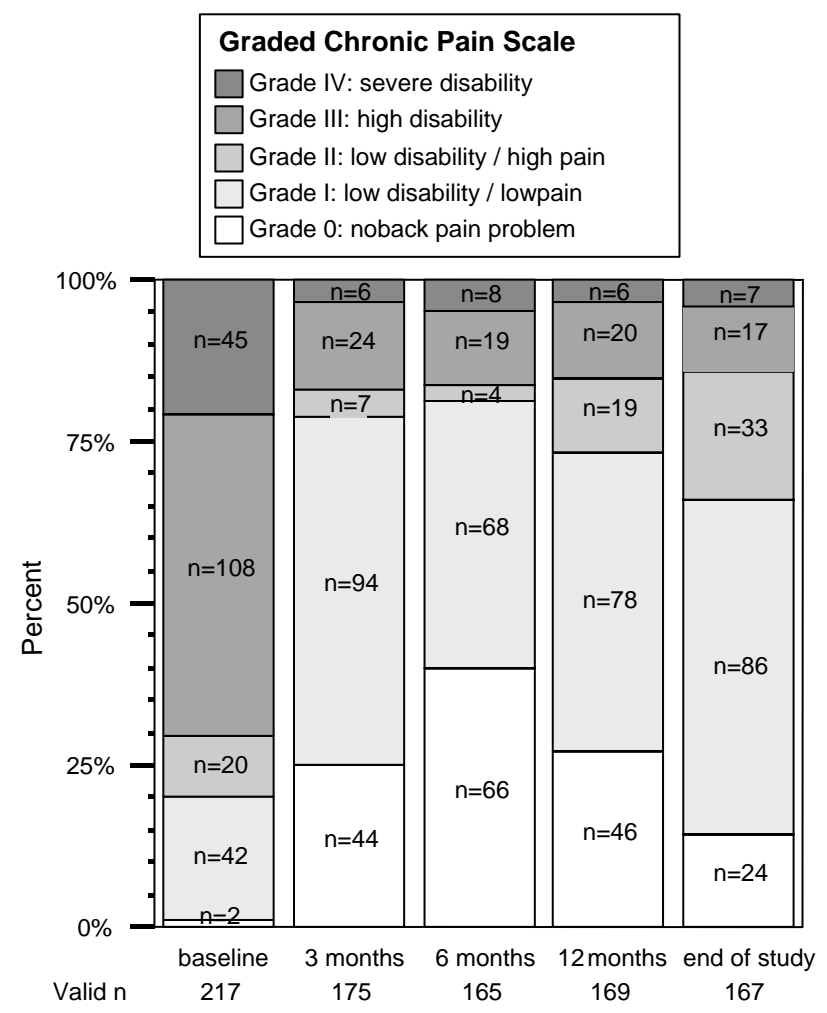

Fig. 1. Graded Chronic Pain Scale Scores during follow-up.

intensity and disability with GCPS are inherent to the way GCPS scores are calculated from pain and disability items.

\subsection{Ordinal regression analysis results}

Of the standard risk factors, age, level of education, number of previous episodes and pain intensity contributed to the prediction of outcome (results consistent for all follow-up measurements) and were selected for use in further analyses.

A backward procedure was carried out to determine the additional predictive value of pain-related fear in explaining end of study chronic pain grade (Table 4).

According to the backward elimination approach, all pain-related fear variables and interaction effects with follow-up time were removed from the model. Details for the final model are presented in Table 5. Odds ratios and confidence intervals showed number of previous episodes and baseline pain intensity to be significant risk factors.

Another backward procedure was carried out to determine the predictive value of several fear-avoidance model variables together. Pain catastrophizing (PCS) was kept out of the model because of its conceptual overlay and correlation with pain-related fear (TSK) and negative affect (NEM). The remaining six fear-avoidance variables (negative affect, TSK-somatic focus, TSK-activity avoidance, avoidance of activities, BDI negative view of self and disability) were subject to stepwise removal; age, pain intensity, number of previous episodes and level of education were initially entered and not to be removed. 
Table 3

Fear-avoidance variables: descriptives and correlations ${ }^{\mathrm{a}}$ with outcome

\begin{tabular}{|c|c|c|c|c|c|c|c|}
\hline \multirow{2}{*}{$\begin{array}{l}\text { Variable base- } \\
\text { line }\end{array}$} & \multicolumn{2}{|c|}{ Descriptives $^{\mathrm{b}}$} & \multirow{2}{*}{$\begin{array}{l}\text { GCPS baseline, } \\
N=217\end{array}$} & \multirow{2}{*}{$\begin{array}{l}\text { GCPS } 3 \text { months, } \\
N=175\end{array}$} & \multirow{2}{*}{$\begin{array}{l}\text { GCPS } 6 \text { months, } \\
N=165\end{array}$} & \multirow{2}{*}{$\begin{array}{l}\text { GCPS } 12 \\
\text { months, } N=169\end{array}$} & \multirow{2}{*}{$\begin{array}{l}\text { GCPS end of } \\
\text { study, } N=167\end{array}$} \\
\hline & Median & Q1-Q3 & & & & & \\
\hline NEM & 4 & $1-7$ & 0.014 & 0.098 & 0.074 & 0.143 & $0.215^{*}$ \\
\hline $\begin{array}{l}\text { Pain intensity } \\
\text { (VAS) }\end{array}$ & 48 & $27-64$ & $0.501 *$ & $0.303 *$ & 0.128 & 0.144 & $0.186^{*}$ \\
\hline PCS & 13 & $8-20$ & $0.226^{*}$ & $0.205^{*}$ & $0.254 *$ & $0.174 *$ & $0.189^{*}$ \\
\hline $\begin{array}{l}\text { Avoidance of } \\
\text { activity }\end{array}$ & 2 & $0-7$ & $0.405^{*}$ & $0.180^{*}$ & $0.255^{*}$ & $0.249^{*}$ & $0.175^{*}$ \\
\hline $\begin{array}{l}\text { BDI-neg. view } \\
\text { self }\end{array}$ & 0 & $0-1$ & 0.094 & 0.104 & $0.165^{*}$ & $0.197 *$ & $0.265^{*}$ \\
\hline $\begin{array}{l}\text { TSK-somatic } \\
\text { focus }\end{array}$ & 8 & $7-10$ & $0.159^{*}$ & 0.092 & -0.023 & 0.100 & 0.110 \\
\hline $\begin{array}{l}\text { TSK-act. avoid- } \\
\text { ance }\end{array}$ & 16 & $13-20$ & $0.284^{*}$ & 0.145 & -0.070 & 0.092 & $0.184 *$ \\
\hline QBPDS & 41 & $28-54$ & $0.728 *$ & $0.222 *$ & 0.130 & $0.236^{*}$ & $0.233^{*}$ \\
\hline
\end{tabular}

$P$-values $\leq 0.05$ are marked $*$.

a Spearman's $\rho$ correlation coefficients are presented.

b Descriptives are baseline values: Q1-Q3 = interquartile range.

Table 4

Backward stepwise regression analysis report with end of study Graded Chronic Pain Scale as a dependent variable and baseline pain-related fear characteristics as independent variables $(N=158)$

\begin{tabular}{|c|c|c|c|c|c|c|c|}
\hline Step & $\begin{array}{l}\text { Variables in } \\
\text { model }\end{array}$ & $\begin{array}{l}\text { Variable } \\
\text { removed }\end{array}$ & $-2 L L$ & $\mathrm{df}$ & $R^{2}$ & LR test & Sign. \\
\hline 0 & $\begin{array}{l}\text { [a] known risk } \\
\text { factors }^{\mathrm{a}} \\
\text { [b] follow-up } \\
\text { time }^{\mathrm{b}} \\
\text { [c] disability } \\
\text { [d] TSK somatic } \\
\text { focus }^{\mathrm{c}} \\
\text { [e] TSK activity } \\
\text { avoidance }^{\mathrm{c}} \\
\text { [f] follow-up } \\
\text { pain intensity } \\
\text { [g] follow-up } \\
\text { TSK somatic } \\
\text { focus } \\
\text { [h] follow-up } \\
\text { TSK act. avoid- } \\
\text { ance }\end{array}$ & & 50.004 & 11 & 0.286 & & \\
\hline 1 & $\mathrm{a}, \mathrm{b}, \mathrm{d}-\mathrm{h}$ & [c] disability & 49.999 & 10 & 0.286 & 0.005 & 0.944 \\
\hline 2 & $\mathrm{a}, \mathrm{b}, \mathrm{d}-\mathrm{f}, \mathrm{h}$ & $\begin{array}{l}\text { [g] follow-up } \\
\text { TSK somatic } \\
\text { focus }\end{array}$ & 49.720 & 9 & 0.285 & 0.279 & 0.597 \\
\hline 3 & $a, b, e, f, h$ & $\begin{array}{l}\text { [d] TSK somatic } \\
\text { focus }\end{array}$ & 49.074 & 8 & 0.281 & 0.646 & 0.422 \\
\hline 4 & $\mathrm{a}, \mathrm{b}, \mathrm{e}, \mathrm{h}$ & $\begin{array}{l}\text { [f] follow-up } \\
\text { pain intensity }\end{array}$ & 48.193 & 7 & 0.277 & 0.881 & 0.348 \\
\hline 5 & $\mathrm{a}, \mathrm{b}, \mathrm{e}$ & $\begin{array}{l}\text { [h] follow-up } \\
\text { TSK act. avoid- } \\
\text { ance }\end{array}$ & 46.378 & 6 & 0.268 & 1.815 & 0.178 \\
\hline 6 & $\mathrm{a}, \mathrm{e}$ & $\begin{array}{l}\text { [b] follow-up } \\
\text { time }\end{array}$ & 46.112 & 5 & 0.267 & 0.266 & 0.606 \\
\hline 7 & $\mathrm{a}$ & $\begin{array}{l}\text { [e] TSK activity } \\
\text { avoidance }\end{array}$ & 44.069 & 4 & 0.256 & 2.043 & 0.153 \\
\hline
\end{tabular}

2LL, - 2LogLikelihood statistic; df, degrees of freedom; $R^{2}$, Nagelkerke pseudo $R^{2}$; LRtest, likelihood ratio test of variable removed; sign., $P$-value for variable removed.

${ }^{\text {a }}$ Known risk factors: age, level of education, number of previous episodes, pain intensity.

${ }^{\mathrm{b}}$ Follow-up time: number of days between baseline and end of study questionnaire.

c Measured at baseline. 
Table 5

Prediction of end of study Graded Chronic Pain Scale: final model details

\begin{tabular}{lcccc}
\hline $\begin{array}{l}\text { Predictor } \\
\text { variable }\end{array}$ & par. est. & $\mathrm{OR}^{\mathrm{a}}$ & $95 \% \mathrm{CI}$ & \\
\hline Age & 0.020 & 1.020 & 0.989 & 1.051 \\
$\begin{array}{l}\text { Number of } \\
\text { previous }\end{array}$ & 0.773 & 2.166 & 1.629 & 2.881 \\
$\begin{array}{l}\text { episodes } \\
\text { Level of }\end{array}$ & -0.204 & 0.815 & 0.593 & 1.121 \\
$\begin{array}{l}\text { education } \\
\text { Baseline }\end{array}$ & 0.017 & 1.017 & 1.004 & 1.030 \\
pain inten- & & & & \\
sity & & & & \\
\hline
\end{tabular}

par. est. $=$ parameter estimate $\mathrm{OR}=$ odds ratio $; 95 \% \mathrm{CI}=95 \%$ confidence interval of odds ratio.

a Ordinal regression OR compares the odds of outcome being above vs. below each of the possible cutpoints (grades I-IV vs. grade 0, grades II-IV vs. grade 0 or I, etc.) when the independent variable increases with 1 unit.

The final model explaining end of study Graded Chronic Pain Scale scores included age, pain intensity, number of previous episodes, level of education and negative affect.

Similar results were found for the prediction of 3, 6, and 12 months' chronic pain grades; pain-related fear variables were removed from the model each time. Secondary analyses in which 3 and 6 months' variables were, respectively, used as predictors of end of study GCPS did not confirm pain-related fear to be relevant at a later stage during follow-up either (disability was only significant predictor).

\subsection{Post hoc analyses}

After interpreting and discussing these results, some post hoc analyses have been performed on alternative models. As the backgrounds of these analyses are best explained within the context of the discussion, they are presented in Section 4.

\section{Discussion}

The aim of the present study was to test the longitudinal validity of the fear-avoidance model using rigorous methodological, psychological and statistical methods. The results did not clearly support the fear-avoidance model in explaining the transition from acute LBP to long-term outcome.

\subsection{Methodological strengths and weaknesses}

In the present study in-en exclusion criteria were set to explicitly select acute patients consulting with LBP as a primary problem. However, since LBP is known for high comorbidity with other functional disorders and psychiatric symptoms, some degree of 'contamination' may have occurred. On the other hand, it can be argued that this 'contamination' is an inevitable part of the real life situation health care providers have to deal with, and as such should not be eliminated for research validity reasons.
Furthermore, a strict approach was taken with regard to analysis. As recommended by Pincus et al. (2002), we chose to measure multiple fear-avoidance variables, but also considered correlations and conceptual overlay. Adjustment for known risk factors was performed by entering these variables into the model before fear-avoidance variables were considered. The outcome variable used (Graded Chronic Pain Scale) properly reflected the aspect of transition in that it is categorical with proven relevant changes between categories. A critical remark can be made about using an adapted version instead of the original instrument for the secondary measurements in this study. It is unlikely, however, that this has significantly influenced the results.

Another critical comment can be made with respect to sample size and statistical power. Based on incidence rates and data on prevalence of LBP in primary care, the number of participants in this study was expected to be higher. Furthermore, highly fearful patients are underrepresented in our analyses, because we excluded the intervention group or our concurrent trial. This will have reduced statistical power, but probably did not bias results. Still, this is one of the larger studies to date, and a dropout rate of $21.6 \%$ is relatively low compared to similar studies, for example by Klenerman et al. (1995). Nevertheless, recruiting acute patients and following them for more than a year seems to highly interfere with daily GP practice (recruitment) and patient interest and motivation (dropout).

An important topic not addressed by Pincus et al. (2002) is the length of follow-up. A long follow-up period is necessary in prospective cohort studies on LBP outcome. As Von Korff et al. (1993) and Wahlgren et al. (1997) pointed out, LBP runs a capricious course with many patients recovering soon, a few becoming trapped in a chronic pain syndrome, and most dealing with recurrent pain of variable severity. In our opinion, a follow-up time of at least 1 year is required to capture the recurrent nature of LBP. By adding a cross-sectional end of study outcome measurement, the number of patient years covered was almost doubled.

\subsection{Post hoc considerations}

A rather basic and conceptual point of discussion we encountered during this study concerns the definition of LBP outcome and the choice of endpoints. Traditionally, and for theoretical reasons, researchers in chronic pain usually define negative outcome in terms of prolonged disability resulting from an isolated LBP episode. As with this study attention is shifted towards acute/recurrent LBP in primary care patients, we alternatively chose to interpret the Graded Chronic Pain Scale score at end of study as a status report of a patient's LBP career as a whole (including pain and disability, relapses and periods of recovery). In our opinion, this approach more closely resembles reality in general practice; GPs do not follow-up on many distinctly chronic cases, most patients consult periodically with intermittent complaints of both pain and dysfunction. This 
operationalisation of primary outcome may, however, be criticised for being vulnerable to not finding existing associations between pain-related fear and disability as found in chronic patients, because the lower end of the GCPS-spectrum is determined by pain intensity instead of disability. Indeed, we did not find these relations-so do they not exist in acute stages of LBP, or did we fail to detect them? We reanalysed our data along the 'chronic disability' line of investigation. A logistic regression analysis was performed with chronic disability (yes/no) as a dichotomous outcome. Chronic disability was defined as a GCPS score of III or IV at both 6 and 12 months follow-up. The results were similar to those of our primary strategy; no associations were found between baseline fear-avoidance and outcome (disability). However, a drawback of this latter strategy is low power, as not many cases qualified as chronic. On the whole it seems that, whatever approach one may prefer, the only conclusion possible from this set of data is that the fear-avoidance model cannot be confirmed.

Along with the discussion about whether to investigate isolated LBP episodes or entire patient careers, the circularity of the fear-avoidance model further complicates analysis. Although our sample was selected to contain new acute LBP episodes, patients brought their previous LBP experience with them. It must be assumed that the effects of the fearavoidance variables acting in the index episode is visible in our analyses, while earlier influences (that is: in previous episodes) may appear as an influence of fear-avoidance variables, of previous episodes, or both. Therefore, in our primary analysis (including the effect of previous episodes) the true influence of fear-avoidance may be underestimated. We compared this model post hoc to an alternative model not containing the influence of previous episodes. This latter model will result in an overestimation of the effect of fearavoidance; the truth may be somewhere in between both estimates. However, the results show that fear-avoidance was not a significant predictor in either model. From this it can be concluded that, whether or not corrected for previous LBP experiences, within the present sample fear-avoidance variables do not add to the prediction of LBP outcome-not within the light of the indexed episode, nor within the perspective of the development of LBP career.

\subsection{Theoretical and clinical implications}

The results of this study together with that of Burton et al. (1995) do not favour the fear-avoidance model. Opposite evidence is provided by six studies in support of the theory (Buer and Linton, 2002; Fritz et al., 2001; Klenerman et al., 1995; Linton et al., 2000; Picavet et al., 2002; Sieben et al., 2002). However, comparing results and explaining differences found between studies is difficult, as study populations, measures used, follow-up periods and analyses vary highly, thus limiting possibilities to generalize. The current study may add to evidence in that it does not invalidate fearavoidance theory, but at least raises doubt about its role early in a LBP episode. It is beyond dispute that the fearavoidance model is well established as a perpetuating factor once chronicity has developed, but we could not confirm its significance in non-chronic cases.

In an attempt to explain this discrepancy it can be argued that at baseline we captured very early processes, since negative affect turned out to be the only predictive fearavoidance variable at baseline. Negative affect is regarded to be a vulnerability factor and potential precursor of painrelated fear. However, pain-related fear did not become a relevant factor at later stages during follow-up.

Of course it is also possible that no long-term effect of painrelated fear exists at all in this sample. In contrast with many chronic patients, the majority of general practice LBP patients will have learned how to cope with their LBP. Although a recurrent problem, they may have found a way to deal with it and take flare-ups for granted to some extent. Only when an episode is experienced as 'different' from previous ones, painrelated fear may raise to pathological levels. In other circumstances, some degree of fear and avoidance may even benefit acute stage recovery, as it reduces nociception and facilitates tissue healing during the first few days (Wall, 1979). The more 'dangerous' aspect of prolonged avoidance in that it deprives the patient from correcting learning experiences may be less important because these patients are mostly active, working people who nevertheless will (be forced to) resume their normal activities as soon as possible. In this way their pain-related fear will naturally be confronted and reduced before it becomes problematic.

Another option is that the fear-avoidance model alone may be insufficient to explain the transition to chronic LBP. Pain-related fear will only show to be predictive of outcome, if it is the most prevalent pathway to chronicity. A general influence of, for instance, negative affect/depressive mood as a vulnerability factor for chronic pain may be more prevalent and obscure the effect of fear-avoidance at the group level. Future prospective studies might benefit from broadening the scope and including possible co-existing models.

\section{Acknowledgements}

The authors are grateful to the staff of the general practices participating in this study for recruiting patients. Special thanks to Eric Bousema who played an essential role in study management. This study was supported by the Dutch Council for Medical and Health Research (MWNWO); Grant No. 904-65-090.

\section{References}

Andersson GB. Epidemiological features of chronic low-back pain. Lancet 1999;354(9178):581-5.

Atlas SJ, Deyo RA, Keller RB, Chapin AM, Patrick DL, Long JM, Singer D E. The Maine Lumbar Spine Study. Part II. 1-year outcomes of surgical and nonsurgical management of sciatica. Spine 1996;21(15):1777-86. 
Beck AT, Ward CH, Mendelson M, Mock J, Erbaugh J. An inventory for measuring depression. Arch Gen Psychiatry 1961;4:561-71.

Bekkering GE, Hendriks HJM, Koes BW, Oostendorp RAB, Ostelo RWJG, Thomassen J, van Tulder MW. KNGF-richtlijn lage-rugpijn. Nederlands Tijdschrift voor Fysiotherapie 2001;111(Suppl. 3):1-24.

Bosscher RJ, Koning H, Van Meurs R. Reliability and validity of the Beck Depression Inventory in a Dutch college population. Psychol Rep 1986; 58(3):696-8.

Buer N, Linton SJ. Fear-avoidance beliefs and catastrophizing: occurrence and risk factor in back pain and ADL in the general population. Pain 2002;99(3):485-91.

Burton AK, Tillotson KM, Main CJ, Hollis S. Psychosocial predictors of outcome in acute and subchronic low back trouble. Spine 1995;20(6): $722-8$.

Crombez G, Vlaeyen JWS, Heuts PH, Lysens R. Pain-related fear is more disabling than pain itself: evidence on the role of pain-related fear in chronic back pain disability. Pain 1999;80(1-2):329-39.

Deyo RA, Battie M, Beurskens AJ, Bombardier C, Croft P, Koes B, Malmivaara A, Roland M, Von Korff M, Waddell G. Outcome measures for low back pain research. A proposal for standardized use. Spine 1998;23(18):2003-13.

Elliott AM, Smith BH, Smith WC, Chambers WA. Changes in chronic pain severity over time: the Chronic Pain Grade as a valid measure. Pain 2000;88(3):303-8.

Engel CC, von Korff M, Katon WJ. Back pain in primary care: predictors of high health-care costs. Pain 1996;65(2-3):197-204.

Faas A, Chavannes AW, Koes AW, Van den Hoogen JMM, Mens JMA, Smeele IJM, Romeijnders ACM, Van der Laan JR. Practice guideline 'low back pain' [translation] (brief-onder embargo). Utrecht: Dutch College of General Practitioners (NHG); 1996.

Fritz JM, George SZ, Delitto A. The role of fear-avoidance beliefs in acute low back pain: relationships with current and future disability and work status. Pain 2001;94(1):7-15.

Jensen MP, Karoly P. Self-report scales and procedures for assessing pain in adults. In: Turk DC, Melzack R, editors. Handbook of pain assessment. New York: Guilford Press; 1992. p. 135-51.

Kendall NAS, Linton SJ, Main CJ. Guide to assessing psychosocial yellow flags in acute low back pain: risk factors for long term disability and work loss. Wellington, NZ: Accident Rehabilitation \& Compensation Insurance Corporation of New Zealand and National Health Committee; 1997.

Klenerman L, Slade PD, Stanley IM, Pennie B, Reilly JP, Atchison LE, Troup JD, Rose MJ. The prediction of chronicity in patients with an acute attack of low back pain in a general practice setting. Spine 1995; 20(4):478-84.

Kopec JA, Esdaile JM, Abrahamowicz M, Abenhaim L, WoodDauphinee S, Lamping DL, Williams JI. The Quebec Back Pain Disability Scale: conceptualization and development. J Clin Epidemiol 1996;49(2):151-61.

Linton SJ, Buer N, Vlaeyen JWS, Hellsing AL. Are fear-avoidance beliefs related to the inception of an episode of back pain? A prospective study Psychol Health 2000;14:1051-9.

Merskey H, Bogduk N. Classification of chronic pain IASP tasks force on taxonomy. 2nd ed. Seattle, WA: IASP Press; 1994.

Metsemakers JF, Hoppener P, Knottnerus JA, Kocken RJ, Limonard CB. Computerized health information in The Netherlands: a registration network of family practices. Br J Gen Pract 1992;42(356):102-6.

Miller RP, Kori SH, Todd DD. The Tampa Scale for Kinesiophobia. Unpublished report; 1991.

Morley S, Williams AC, Black S. A confirmatory factor analysis of the Beck Depression Inventory in chronic pain. Pain 2002;99(1-2):289-98.

Osman A, Barrios FX, Kopper BA, Hauptmann W, Jones J, O'Neill E. Factor structure, reliability, and validity of the Pain Catastrophizing Scale. J Behav Med 1997;20(6):589-605.

Patrick DL, Deyo RA, Atlas SJ, Singer DE, Chapin A, Keller RB. Assessing health-related quality of life in patients with sciatica. Spine 1995; 20(17):1899-908 [discussion 1909].
Penny KI, Purves AM, Smith BH, Chambers WA, Smith WC. Relationship between the chronic pain grade and measures of physical, social and psychological well-being. Pain 1999;79(2-3):275-9.

Picavet HS, Vlaeyen JWS, Schouten JS. Pain catastrophizing and kinesiophobia: predictors of chronic low back pain. Am J Epidemiol 2002;156(11):1028-34.

Pincus T, Burton AK, Vogel S, Field AP. A systematic review of psychological factors as predictors of chronicity/disability in prospective cohorts of low back pain. Spine 2002;27(5):E109-E20.

Roelofs J, Goubert L, Peters ML, Vlaeyen JWS, Crombez G. The Tampa Scale for Kinesiophobia: further examination of psychometric properties in patients with chronic low back pain and fibromyalgia. Eur J Pain 2004;8(5):495-502.

Schoppink LE, van Tulder MW, Koes BW, Beurskens SA, de Bie RA. Reliability and validity of the Dutch adaptation of the Quebec Back Pain Disability Scale. Phys Ther 1996;76(3):268-75.

Sieben JM, Vlaeyen JWS, Tuerlinckx S, Portegijs PJM. Pain-related fear in acute low back pain: the first two weeks of a new episode. Eur J Pain 2002;6(3):229-37.

Smith BH, Penny KI, Purves AM, Munro C, Wilson B, Grimshaw J, Chambers WA, Smith WC. The Chronic Pain Grade questionnaire: validation and reliability in postal research. Pain 1997;71(2):141-7.

Stegen K, Neujens A, Crombez G, Hermans D, Van de Woestijne KP, Van den Bergh O. Negative affect, respiratory reactivity, and somatic complaints in a $\mathrm{CO} 2$ enriched air inhalation paradigm. Biol Psychol 1998;49(1-2):109-22.

Sullivan MJL, Bishop SR, Pivik J. The Pain Catastrophizing Scale: development and validation. Psychol Assess 1995;7(4):524-32.

Van Damme S, Crombez G, Bijttebier P, Goubert L, Van Houdenhove B. A confirmatory factor analysis of the Pain Catastrophizing Scale: invariant factor structure across clinical and non-clinical populations. Pain 2002;96(3):319-24.

Verbunt JA, Seelen HA, Vlaeyen JWS, Bousema EJ, Van der Heijden GJ, Heuts PH, Knottnerus JA. Pain-related factors contributing to muscle inhibition in patients with chronic low back pain: an experimental investigation based on superimposed electrical stimulation. Clin J Pain; in press.

Vercoulen JH, Bazelmans E, Swanink CM, Galama JM, Jongen PJ, Hommes O, Van der Meer JW, Bleijenberg G. Physical activity in chronic fatigue syndrome: assessment and its role in fatigue. J Psychiatr Res 1997;31(6):661-73.

Verkes RJ, Vanderiet K, Vertommen H, van der Kloot WA, van der Meij J. De MPQ-DLV: een standaard Nederlandstalige versie van de McGill Pain Questionnaire voor België en Nederland. In: van der Kloot WA, Vertommen H, editors. De MPQ-DLV: een standaard Nederlandstalige versie van de McGill Pain Questionnaire. Achtergronden en handleiding. Lisse: Swets \& Zeitlinger; 1989.

Vlaeyen JWS, Linton SJ. Fear-avoidance and its consequences in chronic musculoskeletal pain: a state of the art. Pain 2000;85(3):317-32.

Vlaeyen JWS, Kole-Snijders AMJ, Rotteveel A, Ruesink R, Heuts PHTG. The role of fear of movement/(re)injury in pain disability. J Occup Rehabil 1995;5(4):235-52.

Von Korff M. Epidemiologic and survey methods: chronic pain assessment. In: Turk DC, Melzack R, editors. Handbook of pain assessment. 2nd ed. New York: Guilford Press; 2001. p. 603-18.

Von Korff M, Ormel J, Keefe FJ, Dworkin SF. Grading the severity of chronic pain. Pain 1992;50(2):133-49.

Von Korff M, Deyo RA, Cherkin D, Barlow W. Back pain in primary care. Outcomes at 1 year. Spine 1993;18(7):855-62.

Waddell G. Low back pain: a twentieth century health care enigma. Spine 1996;21(24):2820-5.

Wahlgren DR, Atkinson JH, Epping-Jordan JE, Williams RA, Pruitt SD, Klapow JC, Patterson TL, Grant I, Webster JS, Slater MA. One-year follow-up of first onset low back pain. Pain 1997;73(2):213-21.

Wall PD. On the relation of injury to pain. The John J. Bonica lecture. Pain 1979;6(3):253-64. 